\title{
PELATIHAN MAINTANCE KOMPUTER SMAN PAGAR GUNUNG
}

\author{
Yogi Isro Mukti \\ Program Studi Teknik Informatika; Sekolah Tinggi Teknologi Pagaralam (STTP) \\ Jl. M. Siagim No.75 Kel. Karang Dalo, Dempo Tengah, Kota Pagar Alam \\ Telp/Fax: (0730) 621916 \\ e-mail: yogie.isro.mukti@gmail.com
}

\begin{abstract}
Abstrak
SMAN Pagar Gunung (Pagun) merupakan sekolah menengah daerah yang layak untuk menjadi tempat pengabdian civitas akademika Sekolah Tinggi Teknologi Pagaralam (STTP), hampir semua siswa SMAN Pagun tidak terlalu baik memahami hardware computer, pelatihan ini menjadi bukti semangat berbagi dari civitas STTP, tujuannya akhirnya adalah agar siswa memiliki softskills bidang pemahaman hardware computer. Metode yang digunakan untuk kelancaran kegiatan ini adalah menggunakan pre dan pos tes sehingga dapat langsung diperoleh kesimpulan tingkat pemahaman siswa terhadap materi pelatihan maintenance ini, hasilnya terlihat sangat memuaskan yang mana pada saat dilakukan pre tes tingkat pemahaman siswa terhadap hardware dan maintenance computer tidak terlalu baik dari 10 pertanyaan yang diberikan sama sekali tidak ada siswa yang mampu menjawab 100\% benar, bahkan yang memiliki nilai 9 jawaban benar hanya $2 \%$, yang menjawab 8 benar hanya $3 \%$ dari 20 peserta yang mengikuti pelatihan. Tetapi hasil pos tes sangat menggembirakan dimana terdapat hampir 5\% siswa yang mencapai nilai 10 dan nilai 9 hampir $20 \%$ dari total peserta, sehingga disimpulkan pelatihan sangat penting dan mampu meningkatkan pemahaman yang signifikan.
\end{abstract}

Kata kunci-Pengabdian, STTP, Guru, Blog, Pembelajaran, Materi.

\section{PENDAHULUAN}

Pengaruh teknologi informasi begitu luar biasa, telah merambah pada berbagai sisi kehidupan manusia, perannya sangat dibutuhkan [1]. Peran teknologi yang luar biasa ini mengharuskan semua orang harus belajar dalam pengaplikasiaannya sehingga saat ini pembelajaran teknologi informasi telah dimasukan dalam berbagai jenjang pendidikan, bahkan beberapa lembaga atau pendidikan yang tadinya tidak bersentuhan dengan teknologi informasi saat ini memasukan unsur teknologi sebagai pelajaran pendukungnya, bahkan dijadikan pendukung utama. SMAN Pagun merupakan sekolah menengah atas yang memberikan pelajaran umum pada siswanya, berada cukup jauh didaerah sehingga kurang tersentuh modernisasi dan bantuan dari pemerintah termasuk dalam hal pemahaman siswa terhadap perkembangan teknologi informasi, melihat hal ini civitas akademika melalui LPPM dan peserta pengabdian kepada masyarakat dengan semangat berbagi melakukan pelatihan maintenance computer.

Berdasarkan observasi yang dilakukan oleh tim observasi, pelatihan dan penambahan softskills ini salah satu yang sangat diperlukan siswa SMAN Pagun, padahal teknologi informasi merupakan core keilmuan dari civitas akademika STTP, berdasarkan penelitian .... Pelatihan secara langsung akan meningkatkan pemahaman para siswa/peserta pelatihan [], lebih lanjut pelatihan akan meningkatkan imajinasi perserta pelatihan sehingga apa bila ditemukan permasalahan baru oleh peserta pelatihan, maka dia dapat menyelesaikan permasalah yang ada dengan pikirannya sendiri, semangat peserta pelatihan sangat luar biasa tetapi penyelenggara hanya menerima 20 orang peserta pelatihan dengan harapan peserta yang mengikuti pelatihan dapat berbagi dengan siswa yang tidak mengikuti latihan. 


\section{METODE}

Pengabdian dilakukan dengan observasi lapangan terlebih dahulu sehingga pada pelaksanaan pengabdiannya bisa langsung mengena dengan kebutuhan masyarakat, atau sesuai keperluan siswa SMAN Pagun, akhirnya diperoleh kesimpulan untuk menambah softskills siswa SMA perlu dilakukan pelatihan manintenance computer, pada saat pelaksanaannya agar pelatihan tepat sasaran maka dilakukan pencarian informasi dengan melakukan tes menggunakan metode pre dan pos tes terhadap para peserta.

\subsection{Tinjauan Pustaka}

Pendidikan memang berlangsung seumur hidup, tetapi pendidikan yang mana yang akan memberikan kesan bermakna? Jawabannya adalah pendidikan di SMAN Pagun, karena di SMA Merupakan lembaga yang banyak memberikan pengetahuan dan keterampilan lebih banyak dibandingkan di rumah tangga dan masyarakat.Pertanyaan selanjutnya adalah apakah SMAN Pagun telah dapat memberikan kesan yang bermakna itu? Dan bagaimana dan dimana proses itu berlangsung. Jawabnya tentu diberikan oleh narasumber di ruang belajar.

Diakui oleh para ahli bahwa pembelajaran di kelas (Ruang Kuliah), bagaikan sebuah "BlackBox", yang susah diungkap kinerjanya tanpa masuk ke dalamnya. Hal itu karena waktu proses itu berlangsung hanya ada guru dan murid yang ada di dalamnya sebagai juru kunci tanpa ada orang lain. Menurut Nur (1998) hasil-hasil penelitian ternyata belum dapat memberikan hasil yang pas strategi atau pembelajaran yang mana yang paling efektif di kelas, karena setiap pembelajaran sangat tergantung dengan: (1) Kekhususan tujuan dan tipe Peserta Didik, (2) Keumuman, yaitu pengelolaan kembali materi yang dipelajari menjadi yang baru, 3) Pemantauan yang efektif, (4) Keyakinan pribadi peserta didik akan kegunaan hasil kalau mereka mau belajar keras.

Pernyataan Nur memang sangat menantang untuk dilakukan kajian secara terus menerus, karena Chaeruman, Anes Uwes (Jurnal Teknodik, Agustus 2007) menyebutkan bahwa dengan mengunakan teknik "jeda strategis" dalam setiap 30 menit pembelajaran akan membawa siswa memiliki kesegaran konsentasi belajar dan daya ingatnya meningkat. Hal itu dilakukan dengan membuat kuis, pertanyaan lucu, humor, dan menayangkan karikatur yang mengandung humor.Jadi, jeda strategis ini dapat digunakan dalam meningkatkan kesenangan belajar dan pada gilirannya membantu anak dalam mencapai hasil belajar lebih optimal.

Sementara pada tahun 2000, sebuah buku karya Gordon Dryden dan Jeannette Vos berjudul "The Learning Revolution: To Change the way the word Learns " terjemahkan ke dalam Bahasa Indonesia mencatat hampir seluruh keajaiban dalam pembelajaran, lalu menyarankan kita untuk mengikutinya. Di dalam buku ini dikatakan bahwa kebanyakan orang, belajar sangat efektif jika dilakukan dalam suasana yang menyenangkan. Anak miskin akan dapat berkembang kalau mereka melakukan sendiri(mandiri)dalam belajar. Informasi yang kompleks sekalipun dapat diserap dan diingat dengan mudah jika peserta didik benar-benar terlibat di dalam proses pembelajaran. Jutaan remaja saat ini mempelajari dasar-dasar geografi dari sebuah CD ROM bernama Where In The World is Carmken Sadiego? Padahal CD ROM itu hanya dibuat oleh dua pemuda penggemar kuis asal Inowa dan Game komputer, yang ternyata dapat mengubah berbagai aspek dalam belajar menjadi lebih menyenangkan.

Uraian di atas memberikan arah bahwa penting menciptakan suasana belajar yang menyenangkan di kelas dengan pendekatan jeda stategis, yaitu dengan membuat kuis, pertanyaan lucu, humor, dan menanyangkan karikatur yang mengandung humor; dan membuat bahan sajian yang dapat mempermudah pemahaman peserta pelatihan dengan perbantuan komputer sampai pada tingkat lanjut, yaitu melalui pembuatan aplikasi pengolahan nilai dengan demikian kemampuan penggunaan komputer bagi peserta pelatihan perlu dipupuk sedemikian rupa sehingga dapat melahirkan penyajian yang menyenangkan tanpa batas waktu dan tempat sehingga mempermudah pemahaman secara cepat dan praktis.

Pada awal Maret 2006, di Jakarta UNESCO mengundang 20 perguruan tinggi di Indonesia yang memiliki fakultas keguruan untuk mengirimkan seorang dosen, guna mengikuti National Training Programme for Teacher Educators on ICT-Pedagogy Integration yang diadakan AsiaPacific Programme of Educational Innovation for Development (APEID), UNESCO Asia and 
Pacific Regional Bureau for Education dan SEAMEO Regional OpenLearning Center (SEAMOLEC), didanai Japanese Funds in Trust (JFIT).

Program ini mendiskusikan pentingnya pengintegrasian keterampilan ICT (TIK) \& mengajar untuk menciptakan lingkungan belajar yang efektif, inovatif \& menyenangkan.Di dalamnya juga dibicarakan beberapa teknis praktis untuk mengelola presentasi pelajaran dengan $P H P \& M y S Q L y a n g$ efektif. Dengan kata lain,bagaimana agar $I C T$ itu tak sekadar jadi alat bantu, tetapi bagaimana mempertimbangkan taksonomi pembelajaran sehingga ia mampu menjadi sarana untuk mengingat, menganalisis, menilai, menemukan dan mencipta. Semua kreativitas ICT itu didukung oleh Sistem informasi untuk sarana desiminasi dan komunikasi dengan Siswa/I SMAN Pagun.

\subsection{Kerangka Pemecahan Masalah}

Salah satu kegunaan pentingnya pelatihan pengelolaan dan maintenance komputer di SMAN Pagun ini adalah dalam rangka mempersiapan sumber daya manusia (SDM) yang baik di Lingkungan SMAN Pagun, menghasilkan tenaga keja dan alumni yang handal dalam menghasilkan produk kinerja yang diharapkan perusahaan nantinya, dapat menciptakan lingkungan kerja yang berkualitas dan terciptanya pegawai atau tenaga kerja yang ahli dan professional, tentunya di harapkan pekerja yang tercipta tidak hanya membebani keuangan dengan pekerjaannya tetapi profesionalismenya justru menjadikan perusahaan menjadi tambah untung karena karena profesinalismenya itu pekerjaan-pekerjaan yang ringan walau pun di luar tupoksinya alumni SMAN Pagun dapat menanggulangi terlebih dahulu, sehingga di yakini akan mengulangi ongkos pengelolaan dan maintenance sistem di tempat kerjanya, hal ini bagi SMAN Pagun sebenarnya untuk meningkatkan kepercayaan public, terhadap lulusan yang di hasilkan sehingga harapannya ini menjadi nilai tambah dan harapannya seluruh alumni menjadi terserap secara keseluruhan.

Pelatihan pengelolaan dan maintenance ini setelah melihat langsung benar-benar dapat meningkatkan pemahaman siswa terhadap materi yang di sampaikan, tetapi tetap saja waktu yang singkat, hanya beberapa jam saja pelaksanaan pelatihan ini memerlukan alokasi waktu tambahan karena sistem pengelolaan dan maintenance komputer akan maksimal jika sistem ini di kelola oleh seseorang yang benar-benar paham dan ahli, sehingga walau pun bila di lihat dari evaluasi bahwa tingkat pemahaman siswa pelatihan bila di lihat sebelum dan setelah pelatihan berbeda sangat sigifikan tetapi bila siswa ini lebih sering bertemu dan belajar dengan tools dan software komputer yang mana pada saat penanganan ke salahan sangat memerlukan tips dan trik yang khusus, maka sistem yang di kelolanya akan semakin baik dan handal, mendukung pekerjaan secara baik, tentunya hal ini memerlukan pembelajaran dan pengalaman yang mendalam dan lama sehingga tidah hanya aspek teknologi atau cara pengelolaan saja namun bagaimana teknologi ini jadi lebih baik menjadi sebuah sistem yang seolah-olah paling di harapkan (di perlukan) dengan tidak bergantung pada pihak mana pun (mandiri). Oleh sebab itu pelatihan kali ini merupakan langkah awal untuk mencapai tujuan yang lebih besar bukan sekedar pelatihan aplikasi pengolahan data biasa semata.

\section{HASIL DAN PEMBAHASAN}

3.1. Realisasi \& Pemecahan Masalah

Kegiatan pelatihan pengelolaan dan maintenance komputer ini telah dilaksanakan, dengan perincian jadwal dan materi sebagai berikut ini.

\begin{tabular}{|l|l|l|}
\hline \multicolumn{1}{|c|}{ Waktu } & \multicolumn{1}{|c|}{ Materi } & \multicolumn{1}{c|}{ Penyaji } \\
\hline $08.00-09.00$ & Pre Test & \\
$09.00-09.30$ & Persiapan pengenalan & Yogi Isro Mukti, \\
& perangkat keras & M.Kom \\
\hline
\end{tabular}




\begin{tabular}{|l|l|l|}
\hline $09.30-12.00$ & $\begin{array}{l}\text { Panduan maintenance dan } \\
\text { pengelolaan komputer }\end{array}$ & \\
$12.00-12.30$ & $\begin{array}{l}\text { Ishoma } \\
\text { Post-test }\end{array}$ & \\
& & \\
\hline
\end{tabular}

Berdasarkan rangkain pelaksanaan pengabdian maka pelaksanaan pelatihan maintenance computer di SMAN Pagun ini dimulai dengan melakukan pre tes untuk mengetahui tingkat pemahaman para peserta pelatihan mengenal perangkat keras, yang mana rangkaiannya memenuhi table 1 berikut:

Tabel 1. Rincian Kegiatan Pengabdian (PkM)

\begin{tabular}{|c|l|l|}
\hline No & \multicolumn{1}{|c|}{ Jenis Kegiatan } & \multicolumn{1}{c|}{ Penjelasan } \\
\hline 1 & Pre tes & $\begin{array}{l}\text { Pelaksanaan Pre tes untuk mengetahui tingkat } \\
\text { pemahaman peserta pelatihan terhadap perangkat } \\
\text { keras }\end{array}$ \\
\hline 2 & Persiapan pelatihan & $\begin{array}{l}\text { 1. Menyiapkan kebutuhan pelatihan. } \\
\text { 2. Pembagian modul pelatihan. }\end{array}$ \\
\hline 3 & Pelaksanaan pelatihan & $\begin{array}{l}\text { Narasumber menjelaskan materi pelatihan mulai } \\
\text { dari awal: } \\
\text { 1. Menjelaskan perangkat keras komputer. } \\
\end{array}$ \\
& $\begin{array}{l}\text { 2. Menunjukan contoh perangkat keras. } \\
\text { 3. Tanya jawab tentang perangkat keras } \\
\text { komputer }\end{array}$ \\
\hline 4 & Pos tes & $\begin{array}{l}\text { Pada akhir pelatihan dilakukan pos tes untuk } \\
\text { mengetahui pemahaman peserta pelatihan } \\
\text { terhadap materi yang diberikan. }\end{array}$ \\
\hline
\end{tabular}

\subsection{Pembahasan \& Hasil}

Pelatihan yang dilakukan di SMAN Pagar Gunung ini diikuti oleh 15 Orang siswa dan siswi rata-rata anggota OSIS SMAN Pagun, yang mana berdasarkan Gambar 1 dan Tabel 1 diatas tahap pertama adalah pre tes terhadap peserta, yang bertujuan untuk mengetahui pemahaman peserta terhadap teknologi dan system informasi (TSI) dan pemahamannya tentang perangkat keras computer dan maintenance, pertanyaan untuk pre tes ini sebanyak 10 soal, hasilnya seluruh peserta paham akan pentingnya teknologi dan system informasi untuk berbagai aplikasi dan perangkat keras tetapi belum pernah sama sekali mempelajarinya secara langsung, hal ini dapat dilihat pada table 2, dibawah pemahaman peserta hanya pada tahap teori saja, tetapi memiliki semangat untuk mempelajari secara aplikatif, hal ini dibuktikan dengan hasilnya tidak ada peserta yang memperoleh nilai maksimal (100\%) benar hanya terdapat 2 orang yang memiliki nilai 9 atau hanya $\pm 3 \%$ peserta saja.

Berikutnya pada saat pelatihan antusiasme peserta pelatihan makin meningkat, teknologi dan system informasi serta pengenalan perangkat keras komputer membuat peserta makin bersemangat dan memiliki keinginan yang makin kuat untuk lebih mengetahui pembelajaran dengan menggunakan komputer bahkan mereka memiliki niat untuk mengalihkan nantinya belajar sendiri tentang perakitan computer, semangat para peserta ini menghasilkan pemahaman yang baik dan peningkatan pengetahuan hal ini terbukti pada saat akhir pelatihan, pada saat dilakukan pos tes pengetahuan peserta meningkat sangat jauh bila di banding pada saat pre tes, seperti table dibawah ini.

Tabel 2. Tabel Hasil Pre dan Pos tes

\begin{tabular}{|c|c|c|}
\hline & Hasil Test \\
\hline
\end{tabular}




\begin{tabular}{|c|c|c|c|c|c|c|c|}
\hline \multirow[t]{2}{*}{ No } & \multirow[t]{2}{*}{ Komponen } & \multicolumn{3}{|c|}{ Pre-test } & \multicolumn{3}{|c|}{ Post-test } \\
\hline & & \multicolumn{2}{|c|}{ Jumlah } & $\%$ & \multicolumn{2}{|c|}{ Jumlah } & $\%$ \\
\hline \multirow[t]{7}{*}{1} & \multirow{7}{*}{$\begin{array}{l}\text { Konsep } \\
\text { blogging untuk } \\
\text { mendukung } \\
\text { pembelajaran }\end{array}$} & Benar 10 & 0 & 0 & Benar 10 & 3 & 4.5 \\
\hline & & Benar 9 & 2 & 3 & Benar 9 & 4 & 6 \\
\hline & & Benar 8 & 5 & 6.5 & Benar 8 & 4 & 6 \\
\hline & & Benar 7 & 3 & 4.5 & Benar 7 & 2 & 3 \\
\hline & & Benar 6 & 2 & 3 & Benar 6 & 2 & 3 \\
\hline & & Benar 5 & 2 & 3 & Benar 5 & 0 & 0 \\
\hline & & Benar 4 & 1 & 1.5 & Benar 4 & 0 & 0 \\
\hline
\end{tabular}

Peningkatan begitu signifikan yang mana pada saat sebelum dilaksanakan pelatihan ini pemahaman peserta terhadap teori dan aplikasi tidak maksimal tetapi setelah dilakukan pelatihan peningkatannya sangat signifikan sekali, terlihat yang mendapat nilai 10 sebesar $4,5 \%$ dari total peserta yang mengikuti pelatihan, bahkan yang mencapai nilai Sembilan meningkat lebih besar yaitu sebanyak $6 \%$ dari jumlah peserta.

\section{KESIMPULAN}

Maka berdasarkan dari pembahasan dan hasil yang dicapai dari pelaksanaan pelatihan ini dapat diperoleh kesimpulan sebagai berikut:
a. Peningkatan pemahaman peserta pelatihan yang sangat baik.
b. Bertambahnya pemahaman peserta terhadap teknologi dan system informasi
c. Perlu ada pelatihan yang berkesinambungan.

\section{SARAN}

Saran-saran untuk untuk penelitian lebih lanjut untuk menutup kekurangan penelitian. Tidak memuat saran-saran diluar untuk penelitian lanjut.

\section{UCAPAN TERIMA KASIH}

Penulis mengucapkan terima kasih LPPM.

\section{DAFTAR PUSTAKA}

[1] Muslim, B. 2017. Pengantar Teknologi Informasi, Deepublish (CV. Budi Mulia). Yogyakarta

[2] Muslim, B. 2018. Pelatihan aplikasi editing video dengan filmora., Laporan Pengabdian Kepada Masyarakat, LPPM STT Pagaralam.

[3] Hutchinson E. Sarah and Sawyer C. Stacey, 2000, Computers, Communications \& Information, McGraw Hill Companies Inc.

[4] Indonesia Services Education HP Tim, 2001, Manajemen Sistem Belajar Di Dunia Maya, Majalah Info Komputer.

[5] Jeffcoate Judith, 1995, Multimedia In PracticeTechnology and Applications, Prentice Hall International (UK) Limited.

[6] Long Larry and Long Nancy, 2000, Computers 7th Edition, Prentice-Hall Inc.

[7] M.H Jogiyanto, 1995, Pengenalan Komputer, Andi Offset Yogyakarta. 